\title{
A luta contra o câncer na Bahia: de doença invisível a uma questão social
}

\author{
The fight against cancer in Bahia: from an invisible \\ disease to a social issue \\ Christiane Maria Cruz de Souza \\ Professora do Instituto Federal de Educação, Ciência e Tecnologia da Bahia \\ Rua Oscar Carrascosa, 160/201 \\ 40130-010 - Salvador - Bahia - Brasil \\ christianecruz@hotmail.com
}

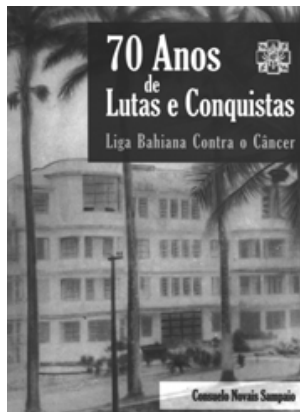

SAMPAIO, Consuelo Novais. 70 Anos de lutas e conquistas: Liga Bahiana Contra o Câncer. Salvador: LBCC 2006. 190p.

\begin{abstract}
omo o título deixa evidente, o livro 70 anos de lutas e conquistas: Liga Bahiana Contra o Câncer, de Consuelo Novais Sampaio, é uma obra comemorativa, voltada para um público heterogêneo. Entretanto, a obra traz interessantes subsídios para a historiografia da saúde na Bahia, contribuindo também para ampliar os conhecimentos sobre a história da doença no Brasil.

Conforme observa a própria autora, trata-se de uma obra de referência, especialmente, acreditamos nós, para quem deseja trabalhar com temas como filantropia e assistência à saúde na Bahia, a partir das primeiras décadas do século XX.

Para escrever a história da Liga Bahiana Contra o Câncer, Sampaio respalda-se em farta documentação escrita e imagética, muitas das quais estão sob a guarda do Memorial Aristides Maltez. A rica iconografia e inúmeras fotografias que integram o texto ajudam a compor a cena em que a história se desenrola.
\end{abstract}

A autora escolhe para marco cronológico a constituição da Liga Bahiana Contra o Câncer, em 1936. A partir daí, o livro se desdobra em seis capítulos, cujos títulos sugerem a posição tomada pela autora em relação aos fatos estudados: "Tempos heroicos (19361945)"; “Arrancada decisiva (1945-1964)"; “Anos sombrios (1964-1980)"; “Luta e renovação (1980-1990)"; “Vitória consolidada (1990-2000)"; “A Liga Bahiana Contra o Câncer no século XXI".

Os dois primeiros capítulos tratam da gênese e da sedimentação da Liga na Bahia. O primeiro capítulo apresenta os passos iniciais para a formação dessa instituição, destacando o engajamento de médicos e de senhoras da sociedade baiana nesse processo. Mostra como a doença ganha visibilidade através das campanhas educativas empreendidas pela Liga com o objetivo de mobilizar a sociedade, explicar a doença e enfatizar a importância da prevenção. O segundo capítulo trata da fundação do Hospital Aristides Maltez, que, segundo a autora, foi a primeira instituição brasileira, de cunho filantrópico, especializada no tratamento do câncer. Nesse capítulo, a autora discorre sobre o esforço para qualificar 
profissionais na área de oncologia e aparel har o novo hospital com as inovações tecnológicas, em meio à crise do pós-guerra.

Com o sugestivo título de "Anos sombrios (1964-1980)", o terceiro capítulo discute as dificuldades enfrentadas pela Liga após a implantação da ditadura militar. Sampaio destaca o movimento de reação liderado pelo seu presidente Carlos Maltez, que congregou representantes de instituições médicas e filantrópicas de todo o país, com o fim de criar estratégias de sobrevivência em meio à crise.

No capítulo seguinte, que cobre o período de 1980 a 1990, a autora demonstra que a redemocratização não atenuou a crise, agravada por sérias dificuldades financeiras, que resultaram em greve dos hospitais, e pela transição do Instituto Nacional de Assistência Médica da Previdência Social (Inamps) para o Sistema Único de Saúde (SUS). Nesse contexto, foram lançadas campanhas visando à recuperação das finanças da instituição, que envolveram toda a sociedade.

O processo de superação é analisado nos dois últimos capítulos. A autora destaca os resultados positivos alcançados, apesar do longo período de turbulência: a expansão da Liga para municípios do interior do estado e a introdução de novas tecnologias para um tratamento mais eficiente e humanizado.

Ao longo da narrativa, despontam as personagens e instituições envolvidas no processo de transformação do câncer de problema médico em "questão social relevante", conforme afirmava, na década de 1940, o professor Estácio de Lima (p.35). Consuelo Sampaio não esconde sua admiração pelos atores que deram visibilidade a uma doença silenciosa, que, até as três primeiras décadas do século $\mathrm{XX}$, não representava uma questão de saúde pública na Bahia.

No texto de Sampaio os pioneiros assumem o papel de heróis, destacando-se, entre eles, a figura do médico baiano Aristides Pereira Maltez. O interesse de Aristides Maltez pelo câncer remonta ao período que estudava na Faculdade de Medicina da Bahia e se intensifica após a conclusão do curso, em 1908. A autora não explicita, mas é provável que durante o curso de especialização em ginecologia, realizado no Hospital Presbiteriano de Nova York, Aristides Maltez tenha entrado em contato com as teorias sobre a doença em voga nos Estados Unidos e na Europa. O câncer passara a ser tema da literatura e dos congressos médicos internacionais desde os primeiros anos do século XX. Para além dos deveres caritativos, o interesse crescente dos médicos brasileiros pelo assunto vinculava-se também à possibilidade de pertencer a um novo campo de estudos, de amplitude internacional, em um contexto de crescente especialização da medicina (Teixeira, Fonseca, 2007).

Em sua prática diária como ginecologista, Aristides Maltez entra em contato com pacientes afetadas pelo câncer do colo do útero ese comove com o sofrimento e as dificuldades existentes para o tratamento. Nesse período, os estudos sobre a doença ainda eram incipientes, e o Hospital da Santa Casa não dispunha de leitos suficientes para atender a um número crescente de enfermas. O médico resolve, então, fundar uma instituição voltada especificamente para o atendimento gratuito dos portadores da doença, buscando, para tanto, o apoio dos seus pares.

O câncer, entretanto, não era uma doença de notificação obrigatória e não aparecia nas estatísticas oficiais. Mais preocupados em combater as doenças endêmicas e epidêmicas 
que assolavam a Bahia e prejudicavam sua economia, médicos e autoridades sanitárias não apoiaram o projeto de Aristides Maltez.

O interesse pelo câncer só aumentou a partir da década de 1920, quando a doença tornou-se alvo da atenção do Departamento Nacional de Saúde Pública (DNSP), e só em 1935, no Primeiro Congresso Brasileiro de Câncer, surgiram as primeiras propostas de enfrentamento da doença no país (Teixeira, Fonseca, 2007, p.9-10).

Favorecido por uma conjuntura nacional e local positiva, Aristides Maltez conseguiu, enfim, mobilizar as elites e as autoridades públicas em direção ao seu objetivo. Em 1932 fundou a Sociedade de Ginecologia da Bahia, e em 1936 nascia a Liga Bahiana Contra o Câncer, cujo objetivo principal era criar o Instituto de Câncer da Bahia (p.25-31).

Ao relatar a trajetória da Liga, Consuelo Sampaio, historiadora de currículo respeitável e vasta experiência, não se limita a apresentar a história institucional e a história da doença; desvela o processo de construção de uma rede de assistência à saúde na Bahia, no qual a filantropia assume papel de destaque.

\section{REFERÊNCIA}

TEIXEIRA, Luiz Antonio; FONSECA, Cristina

Oliveira.

De doença desconhecida a problema de saúde pública: o INCA e o controle do câncer no Brasil. Rio de Janeiro: Ministério da Saúde. 2007. 